\title{
The All amacrine cell connectome: a dense network hub
}

\author{
Robert E. Marc*, James R. Anderson, Bryan W. Jones, Crystal L. Sigulinsky and James S. Lauritzen
}

Department of Ophthalmology and Visual Sciences, John A. Moran Eye Center, University of Utah School of Medicine, Salt Lake City, UT, USA

\section{Edited by:}

Mariano Soiza-Reilly, Institut du Fer à Moulin (U839), INSERM, France

\section{Reviewed by:}

Narayanan Kasthuri, Harvard

University, USA

Yoshihiko Tsukamoto, Hyogo

College of Medicine, Japan

*Correspondence:

Robert E. Marc, Department of Ophthalmology and Visual Sciences,

John A. Moran Eye Center,

University of Utah School of

Medicine, 65 Mario Capecchi Dr.

Salt Lake City, Utah 84132, USA

e-mail: robert.marc@hsc.utah.edu
The mammalian All retinal amacrine cell is a narrow-field, multistratified glycinergic neuron best known for its role in collecting scotopic signals from rod bipolar cells and distributing them to ON and OFF cone pathways in a crossover network via a combination of inhibitory synapses and heterocellular All::ON cone bipolar cell gap junctions. Long considered a simple cell, a full connectomics analysis shows that All cells possess the most complex interaction repertoire of any known vertebrate neuron, contacting at least 28 different cell classes, including every class of retinal bipolar cell. Beyond its basic role in distributing rod signals to cone pathways, the All cell may also mediate narrow-field feedback and feedforward inhibition for the photopic OFF channel, photopic ON-OFF inhibitory crossover signaling, and serves as a nexus for a collection of inhibitory networks arising from cone pathways that likely negotiate fast switching between cone and rod vision. Further analysis of the complete synaptic counts for five All cells shows that (1) synaptic sampling is normalized for anatomic target encounter rates; (2) qualitative targeting is specific and apparently errorless; and (3) that All cells strongly differentiate partner cohorts by synaptic and/or coupling weights. The All network is a dense hub connecting all primary retinal excitatory channels via precisely weighted drive and specific polarities. Homologs of All amacrine cells have yet to be identified in non-mammalians, but we propose that such homologs should be narrow-field glycinergic amacrine cells driving photopic ON-OFF crossover via heterocellular coupling with ON cone bipolar cells and glycinergic synapses on OFF cone bipolar cells. The specific evolutionary event creating the mammalian All scotopic-photopic hub would then simply be the emergence of large numbers of pure rod bipolar cells.

Keywords: connectomics, retina, networks, hub, bipolar cells, amacrine cells, synapses, gap junctions

\section{INTRODUCTION}

The network spanning photoreceptor input and ganglion cell output in the mammalian retina was detailed by Kolb and Famiglietti (1974) using serial section transmission electron microscope (TEM) imaging. Unlike non-mammalian retinal networks (Famiglietti et al., 1975; Naka et al., 1975), mammalian photoreceptor networks were parsed into discrete cone and rod bipolar cell pathways and, remarkably, rod-driven bipolar cells did not synapse on ganglion cells. So how would scotopic signals reach the brain? The solution was a unique interneuron, the AII amacrine cell (Figures 1A,B), which captured rod bipolar cell input and redistributed it to cone bipolar cells (Figure 1C), using the synaptic endings of cone bipolar cells as adaptors. This motif was unprecedented in any CNS network: a stage in an afferent amplification chain acting as the entire signal output for a qualitative channel to a prior parallel stage, effecting divergence of one signal into channels primarily used by another signal, with additional amplification. While reentrant CNS motifs are wellknown, e.g., layer 6 corticothalamic projections (Da Costa and Martin, 2009), the outflow pattern of the AII cell is unique in its scope and nature. Reconstruction and tabulation of synaptic flow in a single AII amacrine cell was achieved by Strettoi et al. (1992). These TEM studies of AII amacrine cells described an architecture and synaptic partnerships that still cannot be explained by or predicted from physiological data. Conversely, while some features of AII cell connectivity broadly predict its physiological responses, no complete model emerges from these anatomical data. On balance and despite its extensive analysis, the evolution, functional scope and connectivity of the AII amacrine cell remains unclear.

Why do we care about the AII cell at all if alternative paths bypass rod bipolar cells? Put simply, AII paths dominate scotopic vision and appear to set the scotopic threshold. Alternative paths access cone bipolar cells via presumably weaker paths, e.g., small gap junctions between rods and cones (Massey, 2008) or sparse direct contacts with OFF cone bipolar cells (Devries and Baylor, 1995; Soucy et al., 1998; Tsukamoto et al., 2001; Pang et al., 2010, 2012) or ON cone bipolar cells (Tsukamoto et al., 2007; Pang et al., 2010). AII and rod bipolar cells comprise a great fraction of their cognate groups and vastly outnumber those OFF bipolar cells thought to receive rod input (Pang et al., 2012). The AII network has a unique mechanism for achieving the high sensitivity characteristic of mammalian scotopic vision (e.g., Saszik et al., 2002; Frishman, 2006). Finally, threshold scotopic OFF responses of retinal ganglion cells are blocked by strychnine, implying a dominant glycinergic drive, consistent with the key role of AII 
A Non-mammalian

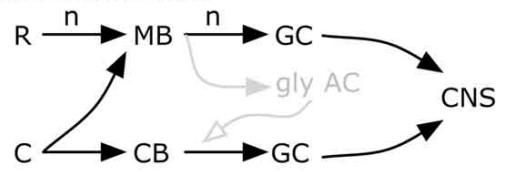

B Mammalian
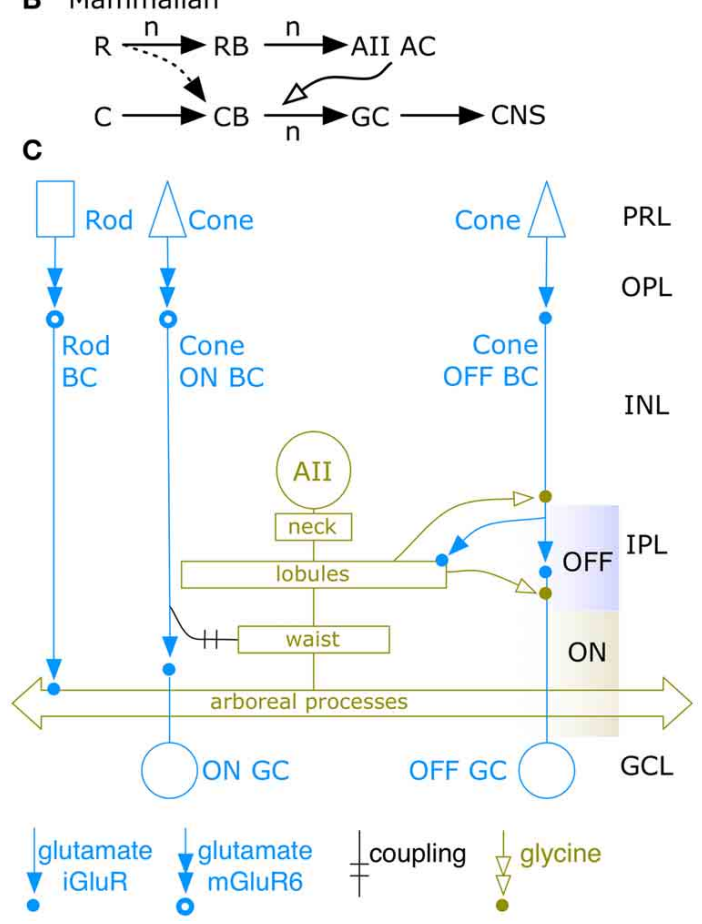

FIGURE 1 | Basic All cell networks. Vertebrate rod $R$ and cone $C$ signal convergence patterns onto bipolar cells, amacrine or ganglion cells, and CNS targets. (A) Non-mammalian networks display two channel types: pure cone bipolar cell (CB) and mixed rod-cone bipolar cell (MB) channels that drive sets of retinal ganglion cells $(\mathrm{GC})$ projecting to CNS targets via high gain (n) glutamate signaling (black arrows). The non-mammalian rod to GC chain has a net gain of $n^{2}$. (B) Mammalian networks display separate $\mathrm{CB}$ and rod bipolar cell (RB) channels. Only CB channels drive GCs. RB channels drive only amacrine cells (ACs), in particular the All AC that provides low gain coupling or glycinergic signaling (open arrow) from the third stage back to stage two in the CB chain. The mammalian rod to GC chain has a net gain of $n^{3}$. There is evidence for sparse rod signal leakage into the CB chain. The gray glycinergic (gly) motif in (A) is the hypothetical evolutionary precursor of the mammalian All AC. (C) The classic All amacrine cell network, circa 1992. The rod input is collected by rod bipolar cells (Rod $\mathrm{BC}$ ) which drive All cells by ionotropic glutamate receptors (iGluRs). Cone input is collected by OFF cone bipolar cells (OFF BC) that also sparsely drive All cells by iGluRs. The All network is extensively coupled to ON cone bipolar cells. Glycinergic output from the All network targets OFF BCs and OFF ganglion cells (OFF GC).

cells in the network (Muller et al., 1988; Arman and Sampath, 2012).

The rod::cone coupling pathway is nominally shared across vertebrates (e.g., Attwell et al., 1984) but there is no evidence that it accounts for the high scotopic sensitivities of mammals. Further, rod convergence onto bipolar cells in mammals is not homologous to the mixed rod-cone bipolar cell cohorts of non-mammalians. The mammalian retina is rod dominated but rod contacts with OFF bipolar cells (Figure 1B) are sparse (Tsukamoto et al., 2001) and can even be missing within target OFF bipolar cell classes ( $\mathrm{Li}$ et al., 2010). Rod input to OFF cone bipolar cells in mammals also appears restricted to a one class of bipolar cell in mouse (Pang et al., 2012) and appears constrained to flow to only a subset of target ganglion cells (Devries and Baylor, 1995; Wang, 2006). In contrast, ectotherms exhibit multiple classes of rod-dominated bipolar cells (Figure 1A) that have precise amounts of cone input (Scholes and Morris, 1973; Scholes, 1975; Ishida et al., 1980). Further, the mixed rod-cone ON pathway in teleost fishes uses different transduction mechanisms for rods and cones (Grant and Dowling, 1996) with distinct positive cationic and negative anionic reversal potentials for rods and cones respectively (Saito et al., 1979). No such weighting or specific transduction appears in mammals. Thus, is it unlikely that the alternative mammalian pathways approach the sensitivity of the AII system. Mammals show high scotopic sensitivity and the sensitive STR (scotopic threshold response) waves of the mammalian electroretinogram are APB-sensitive and kinetically slow, implying the STR depends on rod bipolar cells and, likely, AII cells (Saszik et al., 2002; Frishman, 2006). The unique AII cell and its connectivity thus remains of central interest in the evolution of mammalian rod vision.

Our approach to this problem is based on automated TEM (ATEM) connectomics. ATEM connectomics enables the acquisition of rich synaptic maps by characterizing all partners and structural weights for all synapses and synapse types using connectome volume RC1. Connectome volume RC1 is a synaptic resolution ATEM dataset from rabbit retina spanning the inner nuclear, inner plexiform and ganglion cell layers of a sample field $0.243 \mathrm{~mm}$ in diameter. It currently contains $\approx 890,000$ annotations; $\approx 600$ identified neurons; 6500 conventional and 13,700 ribbon synapses; 26,000 identified postsynaptic sites, over 3800 gap junction pairs, and 2280 adherens junctions; all assembled into 8600 identified presynaptic/postsynaptic partnerships. Volume RC1 specifically contains 39 verified AII amacrine cells, 104 rod bipolar cells, $\approx 300$ cone bipolar cells, and $\approx 200$ amacrine cells, with processes from many more amacrine cells entering the margins of the volume (Anderson et al., 2011b; Marc et al., 2013). This provides us with the opportunity to characterize the complete AII amacrine cell morphology, synaptology, network motifs and synaptic weighting. We have reconstructed 5 cells to statistical completion with large portions of all 39 mapped. This has permitted definitions of all AII partner classes and establishes key synaptic weights for a more comprehensive model of AII cells.

\section{MATERIALS AND METHODS}

The methods for connectome RC1 have been extensively detailed by Anderson et al. (2009, 2011a,b). The RC1 dataset is freely available at connectomics.utah.edu. The associated software is available as free (SerialEM) or open-source applications (Nornir build manager, nornir.github.io/nornir-buildmanager), or via a free license (Viking and Viz web-services tools) for educational use through the University of Utah. The raw RC1 dataset is available on user-provided storage media. 


\section{TISSUE HARVEST AND PROCESSING}

The retinal sample for ATEM image volume RC1 was acquired from a euthanized light-adapted female Dutch Belted rabbit (Oregon Rabbitry, OR). All protocols were in accord with Institutional Animal Care and Use protocols of the University of Utah, the ARVO Statement for the Use of Animals in Ophthalmic and Visual Research, and the Policies on the Use of Animals and Humans in Neuroscience Research of the Society for Neuroscience. At euthanasia, the eye was injected with $0.1 \mathrm{ml}$ fixative with 18 gauge needle pressure relief, enucleated, hemisected, and fixed $24 \mathrm{~h}$ in $1 \%$ formaldehyde, $2.5 \%$ glutaraldehyde, $3 \%$ sucrose, $1 \mathrm{mM} \mathrm{MgSO}_{4}$, in $0.1 \mathrm{M}$ cacodylate buffer, $\mathrm{pH}$ 7.4. Dissected, isolated retinal pieces were immersed in $0.5 \% \mathrm{OsO} 4$ in $0.1 \mathrm{M}$ cacodylate buffer for $60 \mathrm{~min}$, processed in maleate buffer for en bloc staining with uranyl acetate, and processed for resin embedding (Marc and Liu, 2000; Anderson et al., 2009). Retinal blocs were serially sectioned in the horizontal plane at 70-90 nm on a Leica UC6 ultramicrotome onto carboncoated Formvar ${ }^{\circledR}$ films supported by gold slot grids. Optical $70-90 \mathrm{~nm}$ sections were captured and processed for computational molecular phenotyping (CMP) as defined previously (Marc et al., 1995; Marc and Jones, 2002) by probing with antihapten IgGs targeting small molecules: GABA, glycine, glutamate, glutamine, or taurine (Signature Immunologics Inc, Salt Lake City, UT). Small molecule signals were visualized with silverintensification of $1.4 \mathrm{~nm}$ gold granule-conjugated goat anti-rabbit IgGs (Nanoprobes, Yaphank, NY). Optical (8-bit 1388 pixel $\times$ 1036 line frames) images were captured, mosaicked, aligned, and processed for classification (e.g., Marc and Jones, 2002; Anderson et al., 2009). Volume RC1 was bracketed by 10-section optical CMP series and intercalated every 30 sections with one CMP section. This inserted definitive molecular signals into every retinal neuron. The final dataset spanned 401 sections.

\section{VOLUME ASSEMBLY}

RC1 was created as previously described (Anderson et al., 2009, 2011b; Lauritzen et al., 2012). Briefly, the desired field on each grid was captured by SerialEM (Mastronarde, 2005; Anderson et al., 2009) using a Gatan US4000 phosphorimaging camera. Each capture field is an array of $\approx 1000$ tiles captured at $2.18 \mathrm{~nm}$ resolution. Mosaics and $3 \mathrm{D}$ volumes were originally generated using the NCR Toolset (http://www.sci.utah.edu/ download/ncrtoolset). This code has now been superseded by Nornir (nornir.github.io/nornir-buildmanager/). CMP-to-TEM registrations are operator-guided with ir-tweak software from the NCR toolset. Re-imaging for optimized resolution and section tilt is performed using using high resolution $(20,000-60,000 \times)$ goniometric tilt series.

\section{IMAGE VIEWING, ANNOTATION, AND ANALYSIS}

Volume RC1 was visualized and annotated with the Viking viewer (Anderson et al., 2011a). The annotations trace 3D cell architectures as well as locations and dimensions of presynaptic, postsynaptic, adherens, and gap junction motifs as well as non-junctional touches are logged in the Viking database and visualized using VikingPlot, a compiled Matlab application that queries structure information from the annotation database and renders surfaces for display. VikingPlot exports formats for rendering of 3D data in a variety of free (e.g., Blender, blender.org) and commercial applications. The annotation database permits standard SQL queries.

\section{IMAGE PREPARATION}

Publication figure preparation followed Anderson et al. (2009, 2011b). Raw optical image data are available upon request and RC1 is public-access. Multi-modal registered optical images were max-min contrast stretched and sharpened using unsharp masking at a kernel extent of $\approx 540 \mathrm{~nm}$. While ATEM images after NCRToolset and Nornir processing tend to have high contrast, none of the Viking ATEM data shown here except for Figures 9B-D have been processed. Overlay methods for combining optical and TEM images generally computed HSB values for a new image using the TEM gray scale brightness (B) and hue and saturation from $(\mathrm{H}, \mathrm{S})$ from the rgb optical image. Occasionally, fourth or fifth channels were added using alpha blending. Renderings of structures in VikingPlot were created in Matlab 2009a as described in Anderson et al. (2011b).

\section{DATASET ANALYSIS}

Every cell annotation in RC1 is a $2 \mathrm{D}$ disc that is the largest inscribed circle contained by the close shape of the cell's margins (typically a star domain) in a given slice. Internal structures such as gap junctions, presynaptic specializations, postsynaptic densities (PSDs), etc., are linked to a cell via child annotations: $2 \mathrm{D}$ discs representing the child structure's Feret diameter. These annotations, summed over slices, enable quantitative assessments of features (e.g., gap junction and PSD areas) and 3D representations of cells and child structures. These data are accessed via Viking Viz (Anderson et al., 2011a) or Microsoft SQL queries. Large queries were exported as delimited text files. We used AnalystSoft, StatPlus:mac (www.analystsoft.com) for statistics and histogramming.

\section{RESULTS \\ BASIC ATTRIBUTES OF AII CELLS}

The analysis of AII cells in RC1 includes (1) mapping all AII somas and domains, (2) complete $3 \mathrm{D}$ reconstruction of five specific AII neighboring cells (cells 410, 476, 514, 2610, and 3679), (3) classification of contacts with AII cells, and (4) mapping all synapses and gap junctions made by discrete AII cells. Volume RC1 contains 39 AII cells (Figure 2A) corresponding to a density of 841 cells $/ \mathrm{mm}^{2}$ with a center-to-center tile spacing of $34 \mu \mathrm{m}$. The nearest-neighbor soma-to-soma spacing is $30 \pm$ $8 \mu \mathrm{m}$ (mean \pm 1 standard deviation, $n=39$ pairs), consistent with the fact that somas are rarely positioned over the center of a Voronoi tile (e.g., Figure 3B) and the average jitter is about 10\%. Five AII cells were selected for detailed analysis (Figure 2B).

AII cells in RC1 have distinctive features that enable unambiguous classification. They are narrow field glycinergic amacrine cells with somas of $\approx 8-10 \mu \mathrm{m}$ in breadth and thick necks $\approx 5-8 \mu \mathrm{m}$ in diameter that extend deeply into the inner plexiform layer (Figure 3C). The neck is a target of four to six large synapses from $\mathrm{TH} 1$ dopamine/glutamate neurons (Anderson et al., 2011b) and also extends five or six thin stalks 

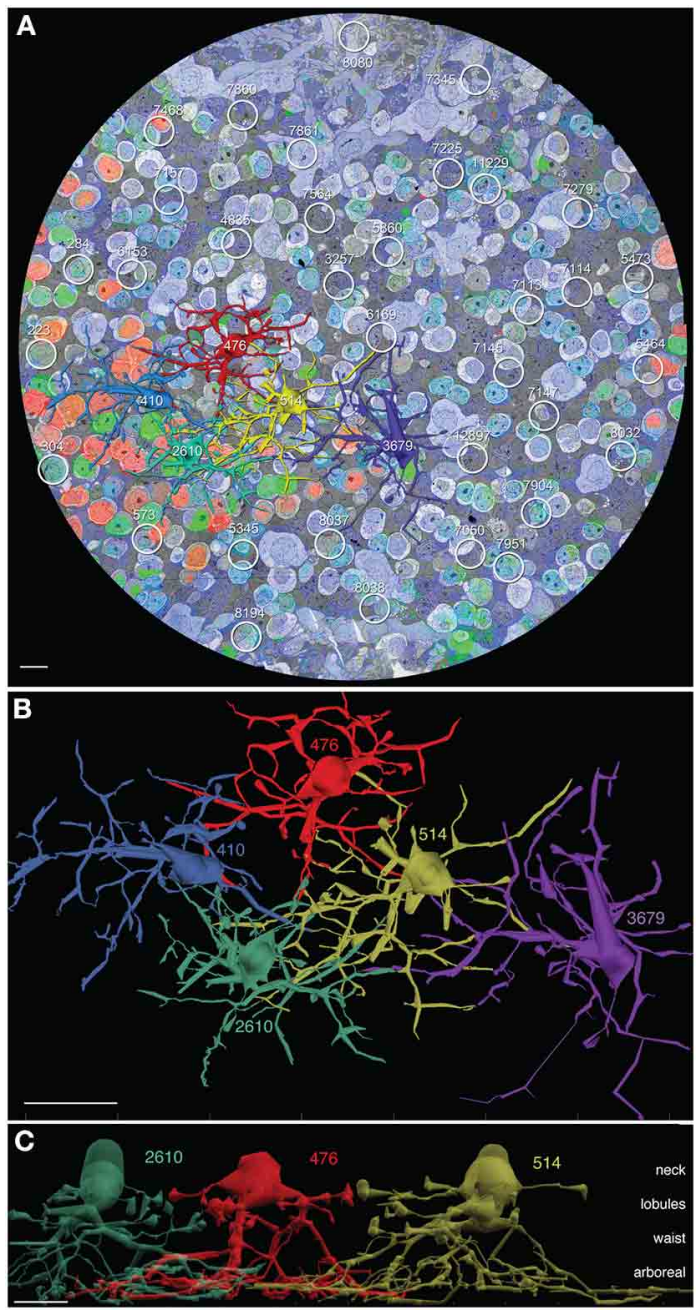

FIGURE 2 | All cells in connectome RC1. (A) Slice z001 with 5 channe molecular overlay (see Anderson et al., 2011b), 5 rendered All cells (410 blue, 476 red, 514 gold, 2610 green, 3679 purple) and 34 other All loci indicated by circles. (B) Top view (XY plane) of VikingPlot rendered All amacrine cells. (C) Side view of All amacrine cells 2610, 476, and 514 laterally displaced to reveal the neck, lobule, waist, and arboreal zones. Scales (A,C) $10 \mu \mathrm{m}$; (B) $20 \mu \mathrm{m}$.
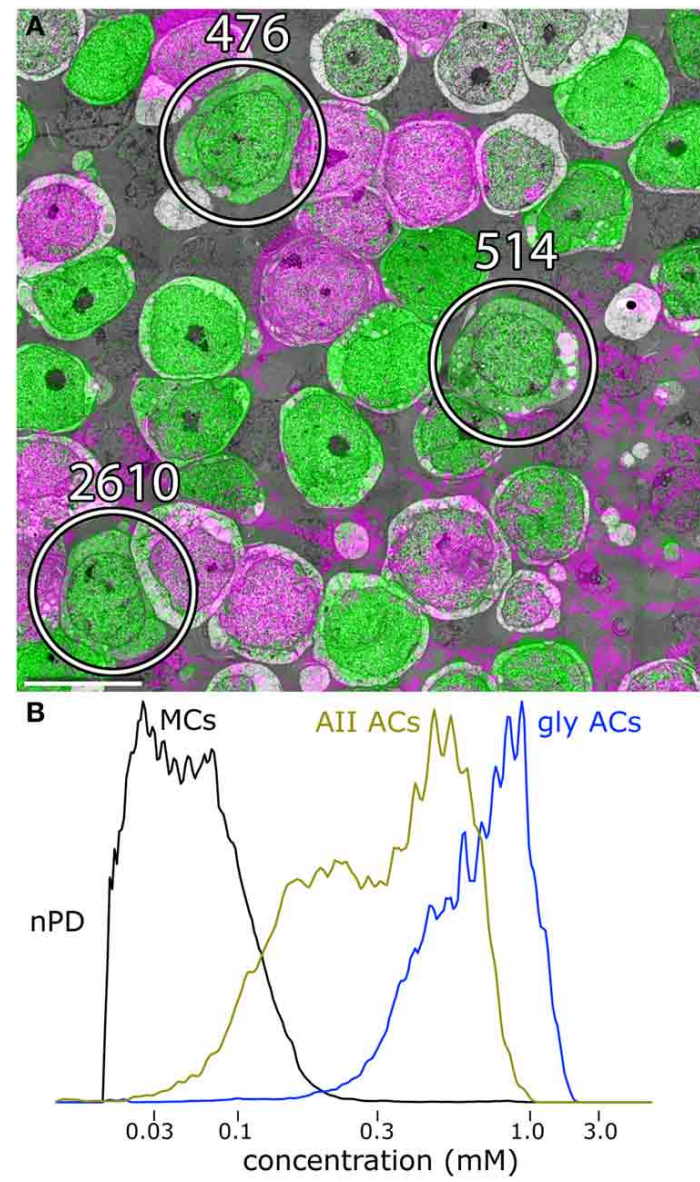

FIGURE 3 | Glycine and GABA signals in amacrine cells. (A) Slice 030, volume RC1. Three of the All amacrine cells are marked. The gray space in between cells is filled with glial Müller cell processes. The pale gray cells are bipolar cells. Scale $10 \mu \mathrm{m}$. (B) Glycine content histograms distinguish All cells from other retinal cells. The glycine content of All cells (All AC, gold trace) is about 2-fold lower than all other glycinergic amacrine cells combined (gly ACs, blue trace), but over 20-fold higher than signals in glial Müller cell (MCs). The histograms each represent aggregate signals from 25 cells calibrated as described in Marc and Jones (2002) and displayed as normalized probability density (nPD) vs. pixel value scaled as concentration.

AII cells are glycinergic, maintaining $\approx 0.6 \mathrm{mM}$ cytoplasmic glycine. Volume RC1 is supported by capstone and intercalated ultrathin optical sections with an array of molecular markers. Figure 3A shows a small section of slice 030 of the inner nuclear layer displaying glycine (green) and GABA signals (magenta) in adjacent amacrine cells. Every AII cell was validated for glycine content by population histograms (Figure 3B). High contrast optical maps of small molecule signals are compliant with ATEM connectomics and significantly assist in tracking neural features (Marc and Liu, 2000; Jones et al., 2003; Anderson et al., 2011b; Lauritzen et al., 2012). Annotation of individual processes often intersects one of the intercalated molecular channels, enabling confirmation of identity, even at the limits of optical resolution. Figure 4 is a set of direct Viking images of serial sections through 


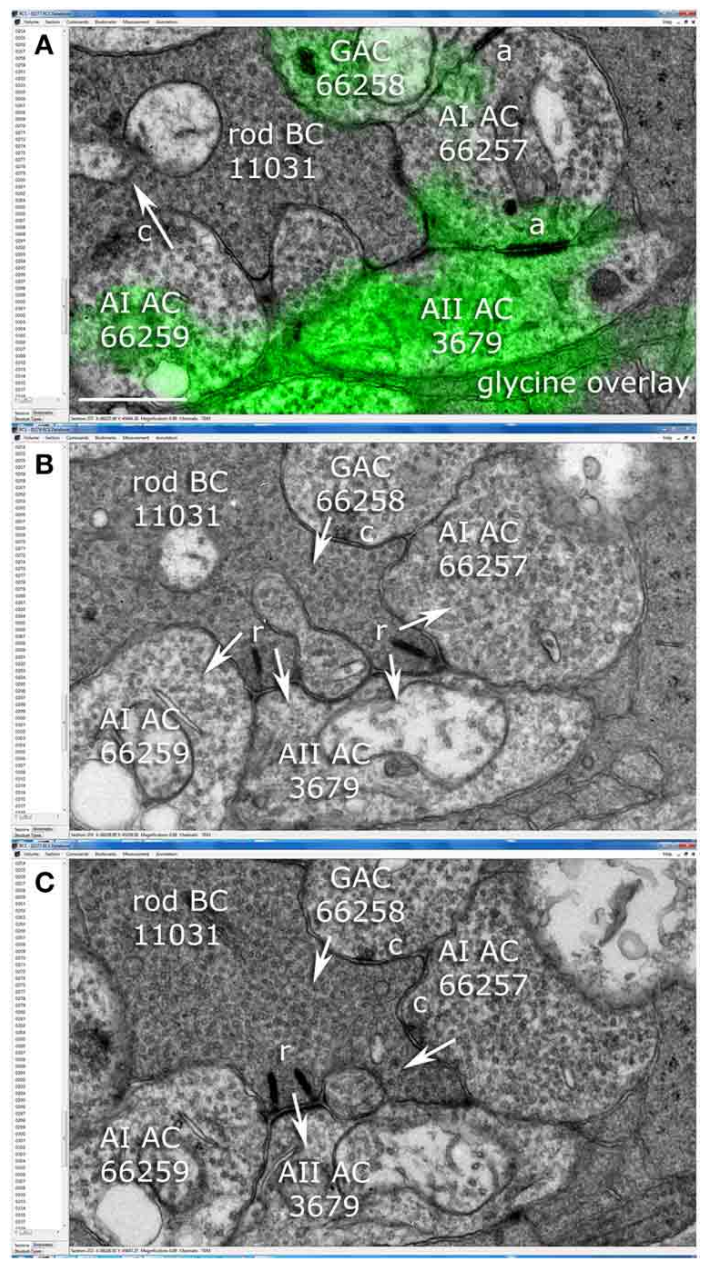

FIGURE 4 | Synaptic relationships among amacrine and rod bipolar cells in the Viking connectome viewer. (A) Slice z277: overlay of glycine channel and TEM. Al cell 66257 forms adherens junctions (a) with All cell 3679 and glycinergic amacrine cell (GAC) 66258. Al cell 66259 forms a conventional synapse (c) onto postsynaptic target (arrow) rod bipolar cell (rod BC) 11031. (B) Slice z274: Rod BC forms two synaptic ribbons (r) onto postsynaptic targets All 3679, Al 66257 and Al 66259.GAC 66258 is presynaptic to rod BC 11031. (C) Slice z272: rod BC forms a third ribbon with All 3679 and Al 66257 forms a feedback synapse. Scale (A), $500 \mathrm{~nm}$.

an AII cell arboreal dendrite as at traverses the surface of a rod bipolar cell. In slice z277 (Figure 4A), a strongly glycine positive arboreal dendrite of AII amacrine cell 3679 approaches one of its target rod bipolar cells (rod BC 11031), as well as a cluster of other amacrine cells. Notably, every AII cell makes large adherens junctions with AI amacrine cells (e.g., AI AC 66257), despite their structural and molecular diversities. As AII 3679 passes rod bipolar cell 11031, it makes three ribbon synapses in a span of 200-250 nm (z274 Figure 4B, z272 Figure 4C). This ribbon cluster also targets two AI cells, one of which is presynaptic to the rod bipolar cell in a classic reciprocal feedback motif. Nearby, a cone-driven glycinergic amacrine cell GAC 66258, part a major cone $\rightarrow$ rod crossover motif, is presynaptic to the rod bipolar cell.

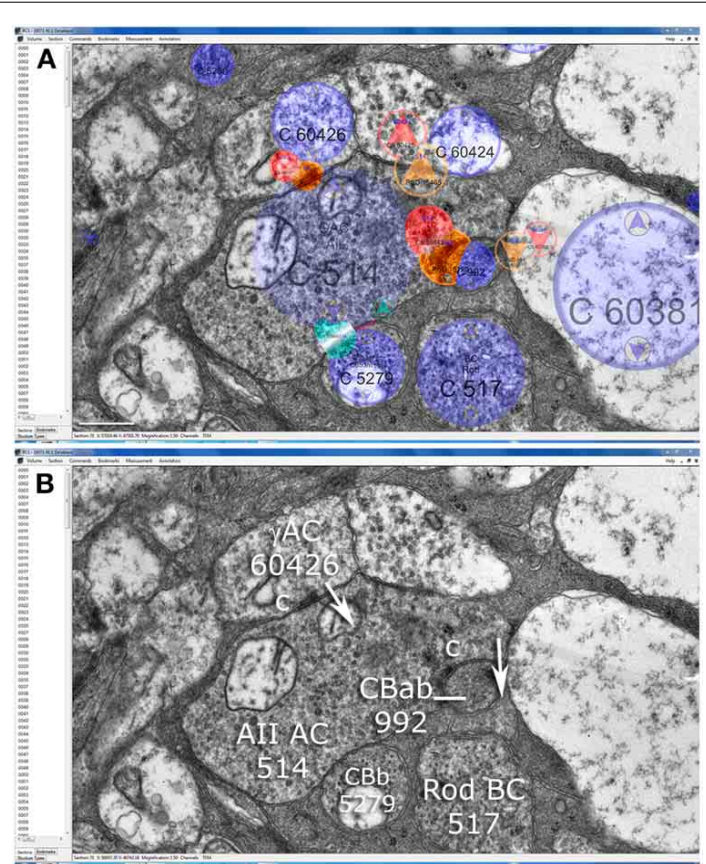

FIGURE 5 | Synaptic patterns of All cell lobules in the Viking connectome viewer. (A) Slice z71 showing annotation overlays for cells (blue), presynaptic elements (red), postsynaptic elements (orange) and touches (cyan). (B) A lobule from All cell 514 is presynaptic to OFF cone bipolar cell CBab 992, postsynaptic to GABAergic amacrine cell $(\gamma \mathrm{AC})$ 60426, and touches ON cone bipolar cell CBb 5279 without making any other specialization. Scale (A), $500 \mathrm{~nm}$.

AII cells display their only synaptic output at the level of the synaptic lobules (Figure 5), which maintain vesicle densities as high as retinal bipolar cells $\left(1488 \pm 171\right.$ vesicles/um ${ }^{3}$, mean \pm 1 standard deviation, $n=7$ lobule sections excluding organelle volumes). The dominant targets of lobules are OFF cone bipolar cells, although AII cells also target specific OFF driven amacrine and ganglion cells (summarized below). AII lobules are complete integration sites as they are postsynaptic to OFF cone bipolar cells and several classes of GABAergic and glycinergic amacrine cells (Anderson et al., 2011b). However, as shown below, the amacrine cell input dominates by far and a typical AII cell can have has few as 3 OFF bipolar cell inputs or as many as 10. Finally, a distinctive feature of AII cells is their extensive homocellular and heterocellular coupling through large gap junctions made by their arboreal processes. Visualization of gap junctions requires at least $2 \mathrm{~nm}$ resolution. Figure 6 displays a triple gap junction complex formed by three of the mapped AII cells in this study. Coupling sites are always accompanied by distinctive adherens complexes. Heterocellular gap junctions are made between AII cells and a range of ON cone bipolar cells (Kolb and Famiglietti, 1974; McGuire et al., 1984; Strettoi et al., 1992; Anderson et al., 2011b; Marc et al., 2013).

\section{LARGE SCALE PARTNERSHIP MAPPING}

Mapping complete synaptic contacts is straightforward and the five AII cells contact between 9 and 17 rod bipolar cells (11.8 \pm 3.3 


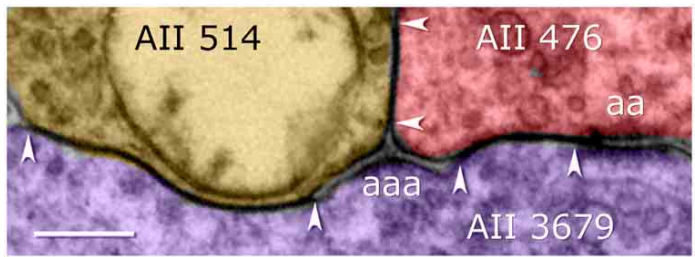

FIGURE 6 | Coupling among arboreal processes of All cells in the Viking connectome viewer. Contiguous gap junctions between arrowheads range $200-500 \mathrm{~nm}$ in extent. All gap junctions are accompanied by dual (aa) or triple (aaa) adherens junctions. Scale, $200 \mathrm{~nm}$

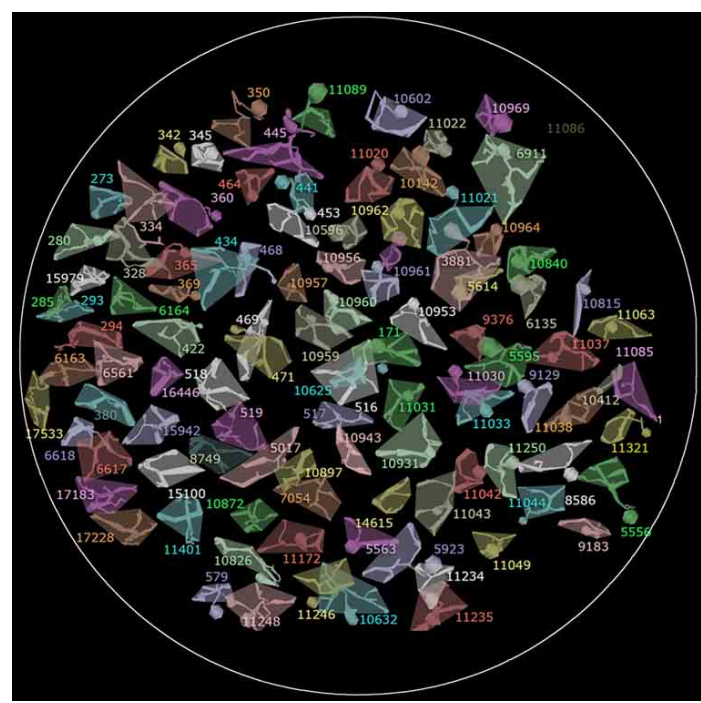

FIGURE 7 | The array of all 104 rod bipolar cell axonal fields in RC1. The shaded polygon represents the convex hull for each cell. In some cases the soma and axon extend at an angle away from the axonal field and are not included in the hull. Circle scale, $0.25 \mathrm{~mm}$.

$\mathrm{SD}, 0.28$ coefficient of variation, CV). Their ribbon sampling is 7 fold more precise, however, averaging $75.6 \pm 3$ ribbons per AII cell with a CV of 0.04 . Rod bipolar cells (Figure 7) are also precise in ribbon expression, with $31 \pm 3.9$ synaptic ribbons/bipolar cell $(n=27)$. The variation in rod bipolar cell contact seems to be completely geometric, representing the overlap of AII arboreal dendrites with rod bipolar cell axonal domains (Figures 8A,B). This difference in precision between cell sampling and synapse sampling is powerful. For a sixth AII cell to increase the synaptic $\mathrm{CV}$ to match the cell sampling $\mathrm{CV}$, it would have to have a ribbon sampling rate 20 SDs larger. Conversely, for AII cell sampling to be as precise as synaptic sampling, the next 20 ACs counted would have to have SDs of zero. This argues that AII cells count synapses, not cells.

When AII amacrine cells encounter other cell classes, they make or decline connections by clearly stereotyped rules in their different compartments. The 39 AII amacrine cells in RC1 encounter each of 104 rod bipolar cells in multiple instances at multiple levels of the inner plexiform layer. Their arboreal

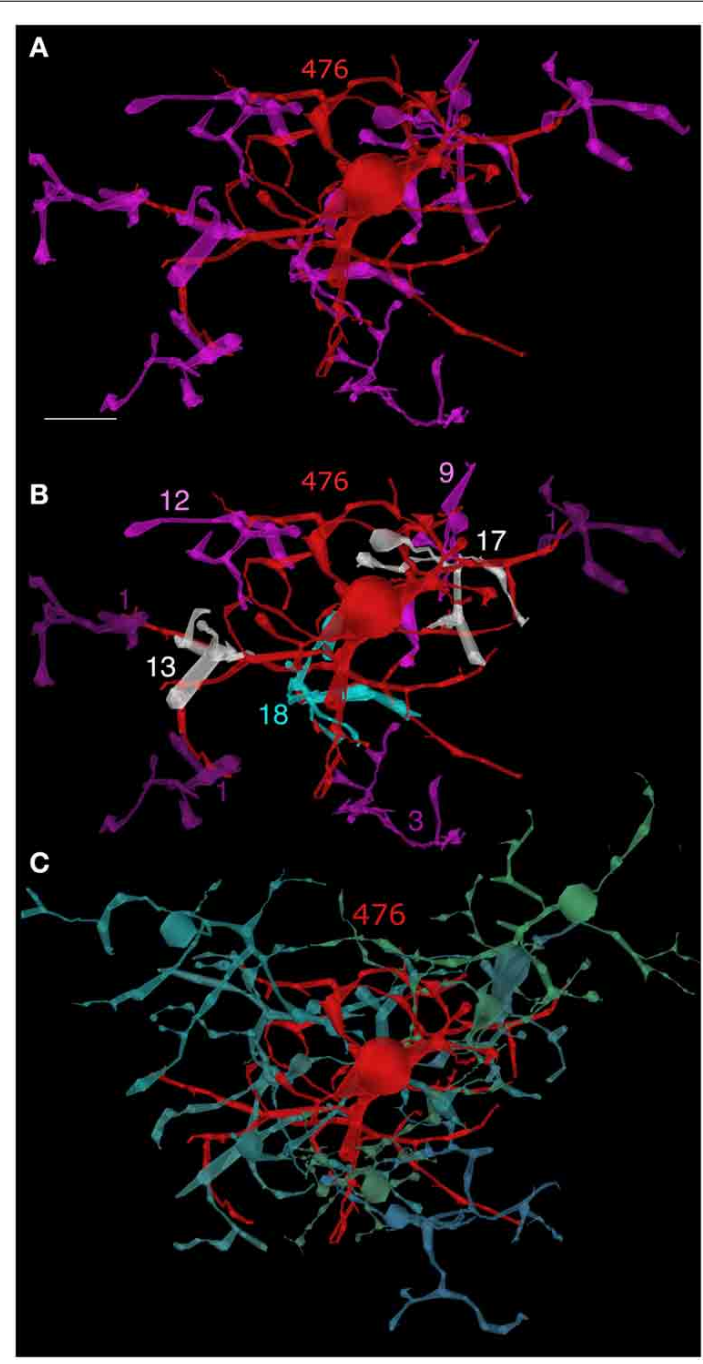

FIGURE 8 | All cell 476-bipolar cell clusters. (A) All cell 476 (red) contacting nine rod bipolar cells (magenta). (B) Contact weights: 1 ribbon (dark purple), 3 ribbons (purple), 9-12 ribbons (magenta), 13-17 ribbons (white), 18 ribbons (cyan). (C) All cell 476-ON cone bipolar cell clusters. Eight $\mathrm{ON}$ cone bipolar cells representing five of the eight known classes make multiple gap junctions with All 476. Scale, $10 \mu \mathrm{m}$

dendrites are always postsynaptic to rod bipolar cells and never presynaptic, in 777 verified encounters from 1246 ribbons. And when lobules encounter rod bipolar cell axons in transit (in 6 validated instances) no ribbon contacts are formed, despite the fact that both rod bipolar cells do make axonal ribbons and will make synapses with AII arboreal dendrites high in the ON layer (Lauritzen et al., 2012). More importantly, AII cells can always distinguish between rod and ON cone bipolar cells by never making gap junctions with rod bipolar cells in the same encounters, and making gap junctions with every validated ON cone bipolar cell ( $n=172$ validated AII-CBb encounters). Similarly, AII lobular dendrites have their own rules. In contacts with 180 different OFF cone bipolar cells, they are presynaptic, postsynaptic, or both, but never form gap junctions, despite the fact that AII and $\mathrm{CBa}$ cells both express connexins. And while AII cell arboreal 
processes make extensive gap junctions with each other at every encounter $(n=525)$, rare instances of direct lobule-lobule contact $(n=6)$ do not show coupling, suggesting that AII connexins are excluded from lobules. Declined connections are more difficult to track, as they require first documenting a "touch" and then tracing both processes to ensure that a contact is not made elsewhere. By tracking the arboreal dendrites of AII cells in validated 11 touches with ganglion cells spanning many microns each, AII cells made no specializations (adherens, gap junctions, or synapses). In contrast, we have tracked an OFF $\alpha$ ganglion cell dendrite as it traversed the entire $\mathrm{RC} 1$ volume, encountering 23 separate AII lobules from 12 validated AII cells in its path. AII lobules also make abundant synapses onto verified GABAergic amacrine cells. Every lobule was presynaptic to the OFF $\alpha$ ganglion cell. But when lobules encounter AI GABAergic amacrine cell processes in the OFF layer (12 validated instances so far), they never make synapses, even though AI and AII amacrine cells make large adherens junctions at the arboreal level (Figure 5A). If we define AII contact errors as making gap junctions with rod or CBa bipolar cells, receiving ribbon from a CBb cell (with the exception of the $\mathrm{CBb} 7$ cell, described below), failing to accept ribbons from rod bipolar cells, or any variation of other detailed associations, we have documented 1773 proper connections (fully identifying both AII cells and the target cell) and 0 improper connections. We have also annotated and additional 3067 contacts between AII cells and targets not yet fully traced. In no case have we documented an obviously aberrant connection. These data suggest that AII cells are effectively errorless in executing their connectivity rules.

The interactions between AII cells and all other classes of neurons are too extensive to detail cell-by-cell, but can be tabulated (Table S1) and graphically summarized. There are 17 signconserving input partners to AII cells: nine glutamatergic and eight coupling. Volume RC1 contains at least six distinct classes of OFF cone bipolar cells and seven classes of ON cone bipolar cells (Marc et al., 2013, 2014) and all of them display partnerships with AII cells. All classes of OFF cone bipolar cells are both presynaptic and postsynaptic to AII cells, with postsynaptic events dominating by over 5-fold. Importantly, a single AII cell rejects input from most OFF bipolar cells and only a few ribbon inputs are permitted (see below).

All classes of $\mathrm{ON}$ cone bipolar cells are coupling partners with AII cells, but only in the waist or arboreal zone. Figure $8 \mathrm{C}$ displays the eight ON cone bipolar cell partners of AII 476, each of which forms multiple gap junctions with the AII at 28 sites: CBb3 6155 (1 gap junction), CBb3 4569 (9), CBb4w 170 (2), CBb4w 324 (1), CBb5w 483 (2), CBb4-5i 6156 (2), CBb5-6i 419 (8), CBb5-6i 4570 (3). While rod bipolar cells dominate the ON polarity input, wide-field, probable blue-sensitive (see Famiglietti, 2008) CBb7 bipolar cells are also presynaptic to AII cells and are unique in also being coupled via gap junctions (Figures 9A-D), which puts them in a position of being sparse amplifiers. We have partly analyzed seven $\mathrm{CBb} 7$ cells from a cohort of a dozen candidate cells that arborize close to the rod bipolar cells and are not part of the $\mathrm{CBb} 3,4$, or 5 sheets. Every cell makes 1-3 three ribbon synapses and 2-7 gap junctions with neighboring AII cells (CBb $180 \rightarrow$ AII As depolarizing rod signals invade $\mathrm{CBb} 7$ cells through gap

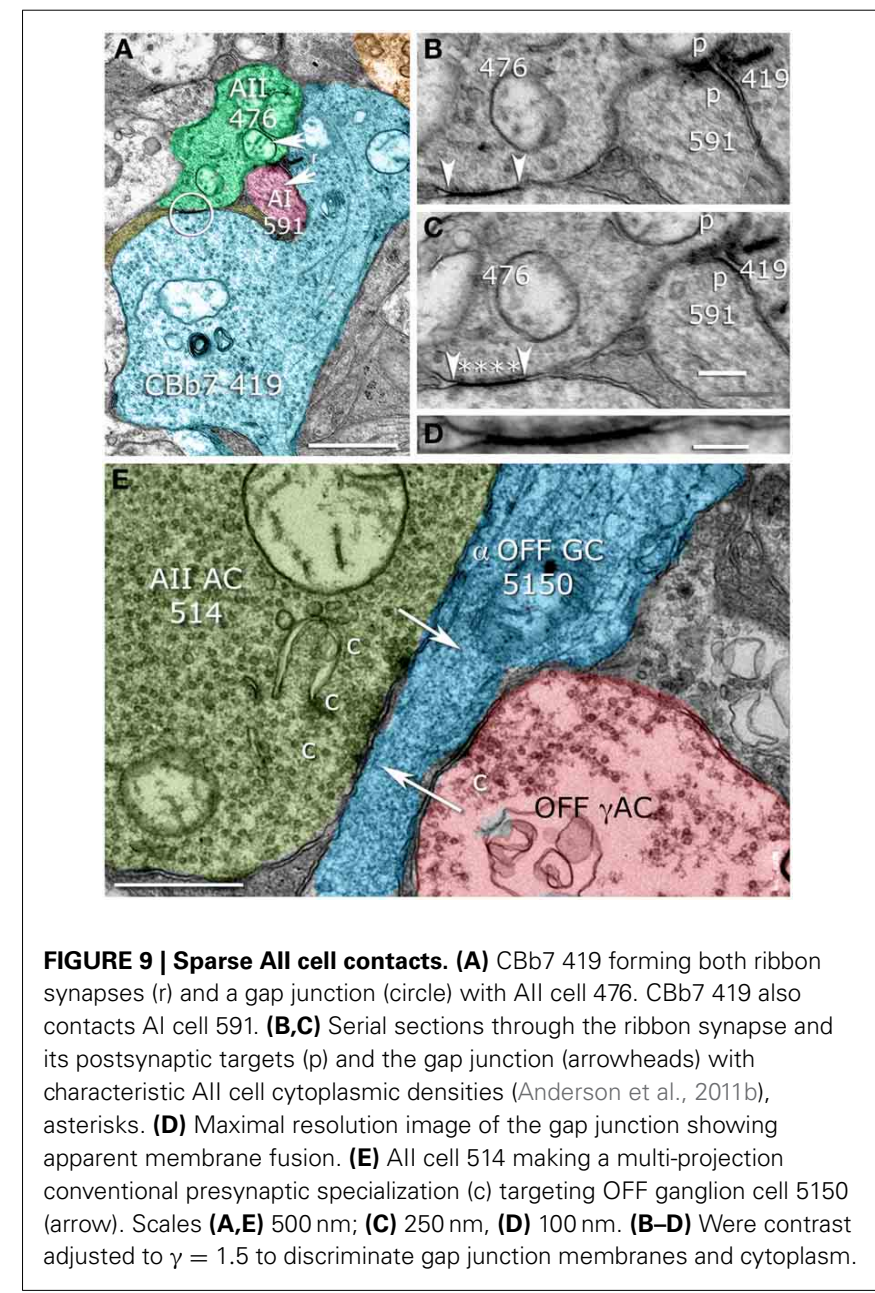

junctions, they can immediately reinforce the signal with synaptic glutamate release. The significance of this small sample is nevertheless high: over 200 mapped non-CBb7 cone bipolar cells never make ribbon inputs AII cells despite making extensive numbers of gap junctions. Conversely all $7 \mathrm{CBb} 7$ cells do make ribbons inputs (Komolgorov-Smirnov, $\alpha=0.01, p=5 \times 10^{-7}$ ).

Finally, the dominant dopaminergic neuron of the mammalian retina is the TH1 (tyrosine hydroxylase positive type 1) axonal cell. It is also a glutamate neuron that is presynaptic to the neck region of AII amacrine cells (Anderson et al., 2011b) through very large synapses. The TH1 inputs are significantly larger than the aggregate $\mathrm{OFF}$ cone $\mathrm{BC}$ inputs and may dominate the photopic ON response of AII cells. This collection of sign-conserving inputs makes the AII cell a formal network hub, but the key to its function lies in synaptic weighting.

Inhibitory input to AII cells spans the retina and includes GABAergic amacrine cells of both OFF and ON varieties, and glycinergic $\mathrm{ON}$ and possible glycinergic $\mathrm{ON}-\mathrm{OFF}$ amacrine cells. At least two classes of GABAergic OFF cells target AII lobules. While it is possible that some of the GABAergic input is also from ON-OFF cells, we have identified several classes of GABAergic ON-OFF amacrine cells that touch but explicitly fail to make any synaptic partnerships with AII cells. So, on balance, it appears that 
the GABAergic drive largely comes from monophasic cone-driven ON or OFF ACs. We have not dissected the weighting analyses of these subgroups, which will take at least another year of annotation, but they outnumber OFF bipolar cell ribbon synapses by $>5$-fold and outweigh them in synaptic area by $>10$-fold. Arboreal dendrites are targeted by GABAergic ON cells driven by cone bipolar cells as well as GABAergic AI amacrine cells in a feedforward motif. There are also narrow-field glycinergic amacrine cell inputs to arboreal dendrites from cone-driven ON and possible ON-OFF amacrine cells. Collectively, the inhibitory drive of the arboreal dendrites represents a cone $\rightarrow$ rod path inhibitory crossover; part of a collection of networks enabling cone signals that may suppress rod signals in the mesopic transition (Marc et al., 2013).

The synaptic outputs of AII cells are completely restricted to the lobules and target all OFF cone bipolar cell classes; GABAergic and glycinergic OFF amacrine cells that are also presynaptic to AI amacrine cells at large inhibitory sites on the proximal AI dendrites (Anderson et al., 2011b); and the dendrites of selected classes of retinal ganglion cells: specifically OFF $\alpha$ and $\delta$ ganglion cells (e.g., Figure 9E). These ganglion cell dendrites are very sparse and not every lobule encounters one. In contrast, every lobule encountered by these specific ganglion cells makes a synapse.

Even with this diversity, we can develop a summarization of signal flow in the AII system. One approach involves mapping all the synapses associated with AII cells into five categories: rod bipolar cell input, off bipolar cell input, amacrine cell synaptic input, coupling and AII synaptic output. Figure 10 summarizes these partnerships for AII cell 2610 in dimensionally correct 3D positioning throughout the inner plexiform layer. Combining such partnership maps for all five cells generates a comprehensive view of the major signal flow architecture for the AII system. By aligning and superimposing all partnerships in the lateral XZ view ( $Z$ spans the IPL), the combined stratification profiles can be visualized (Figure 11A) and extracted into separate components on the same scale: outputs and coupling (Figure 11B), inputs (Figure 11C), and a summary of lateral spread (Figure 11D). The simultaneous visualization of outputs (blue) and coupling

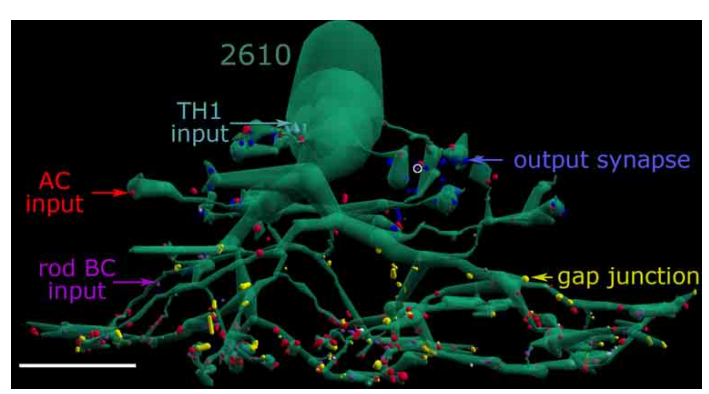

FIGURE 10 | All cell partnerships. All cell 2610 with its rod bipolar cell input (magenta), amacrine cell input synaptic input (red), coupling sites (yellow), TH1 cell input (cyan), and glycinergic synaptic output (blue) dimensionally mapped onto its surface. Small white dots are adherens junctions. A single visible OFF cone $\mathrm{BC}$ ribbon is marked with a white circle. Scale, $10 \mu \mathrm{m}$. (yellow) demonstrates that the differential trafficking and functional assembly of presynaptic proteins for vesicle release into lobules and connexins for coupling into the waist and arboreal dendrites is errorless and defines the border between OFF (blue) and $\mathrm{ON}$ (yellow) layers of the inner plexiform layer, as first proposed by Kolb and Famiglietti (1974). And what we mean by errorless is that every $\mathrm{CBb}$ cell $(>200 \mathrm{CBb}$ cells making $>1000$ gap junctions) is always coupled to the AII cells it contacts, whereas no rod bipolar or CBa cell (>100 each) ever makes a gap junction. Similar counts can be had for all other classes of contacts. These inputs can be stratified into three simple zones (Figures 11B,C): excitatory ON inputs from TH1 cells (cyan), inhibitory OFF inputs (green), inhibitory $\mathrm{ON}$ inputs (red), and excitatory rod bipolar cell inputs (magenta). These can be further refined into finer classes but, for now, this analysis demonstrates

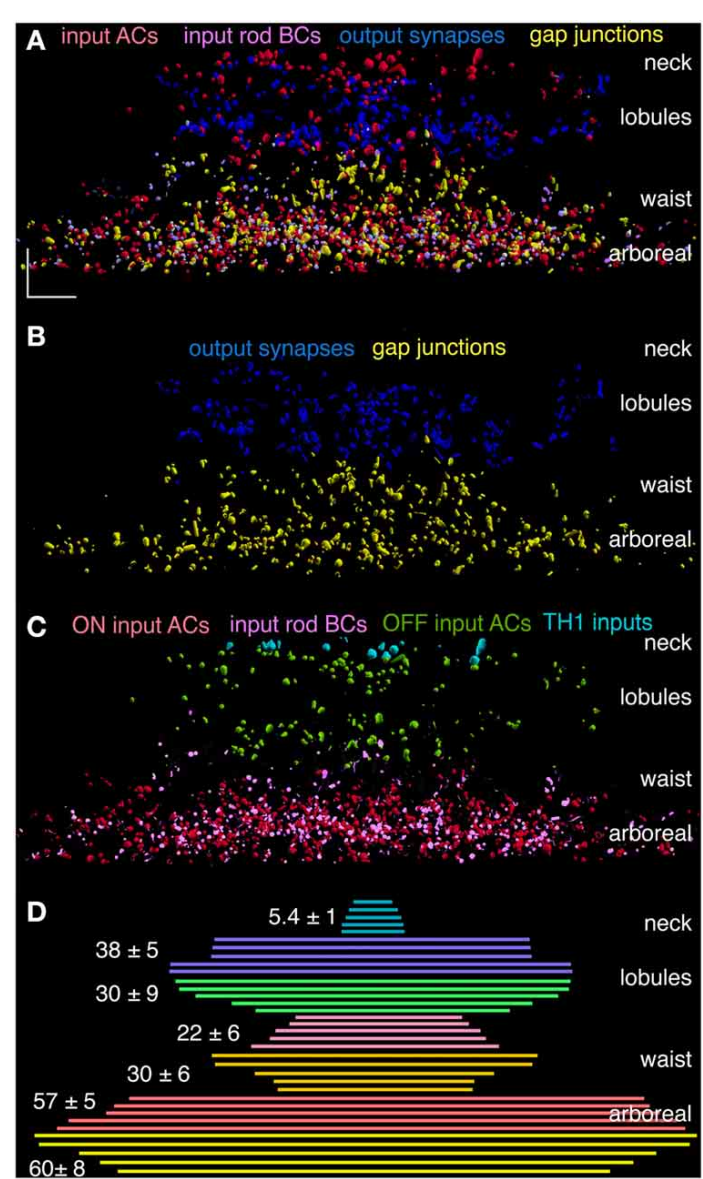

FIGURE 11 | Combined partner distributions for All cells 410, 476, 514, 2610, and 3679. (A) Superimposed AC synaptic input (red), rod BC ribbon input (magenta), coupling (yellow) and synaptic output (blue) mapped onto its surface with stratified anatomical features. (B) Outputs and coupling are completely segregated. (C) Inputs can be parsed into TH1 cell ON (cyan), OFF inhibition (green) and ON excitation (magenta) and ON inhibition (red). OFF excitation is so minimal that it is not visible in the plots. (D) The lateral extents of key stratified zones for each cell are centered and superimposed with the mean $\pm 1 \mathrm{SD}$ width at left. The larger spread for the neck in $\mathrm{C}$ is caused by the misalignment of cell bodies with the center of the dendritic arbor. XY Scale, $10 \mu \mathrm{m}$. 
how we can weight synaptic data from connectomics to build neuronal models. Weighting may require spatial rules as well, and by summarizing the lateral spread of each component we see that the interaction zones of the lobules and the waist are much narrower than the arboreal system. In fact, the lobular radius is only half the distance between cells, resulting in coverage of synaptic space without redundancy. Thus, the distal portion of the AII cell tiles retinal space and its lobules form a sampling grid with an approximate 10-15 $\mu \mathrm{m}$ spacing. The waist and neck subtile the space and their partnership patterns reflect the aggregation of wide-field TH1 cell signals, and the coupled ON cone bipolar cell network (Lauritzen et al., 2013). Finally the arboreal dendrites represent a center-to-center spatial covering, rather than a tile, with an ideal coverage factor of 4 (arboreal area/single cell area), which predicts that every AII cell should be 8 -connected in a $2 \mathrm{D}$ grid. The measured homocellular coupling for eight AII cells whose arboreal dendrites have been completely mapped is $7.6 \pm 0.9$ partners.

These data can be summarized as synaptic area weightings (Figure 12). Partnership patterns were converted to binary images, capturing the location, number, and sizes of contacts, and profiled across the inner plexiform layer by averaging with over the width of the image. This computes the area of an input, coupling or output site and provides the spatial weights for modeling such connections. Based on prior descriptions of AII cells, we were surprised at first to find that inhibitory synapses (mostly ON GABAergic input) dominate the drive, but this is consistent with patterns of signal flow bipolar cells as well (Marc and Liu, 2000 ). The area of $\mathrm{ON}$ amacrine cell input is $\approx 8$-fold higher that rod bipolar cell ribbon input. The integrated AII::AII coupling is approximately $6-7 \mu \mathrm{m}^{2}$ while AII-CBb coupling represents $\approx 1 \mu \mathrm{m}^{2}$. The lobular domain is dominated by output synapse areas, with minor OFF amacrine cell input and negligible OFF bipolar cell input. Finally the neck region is an approximate 1:1

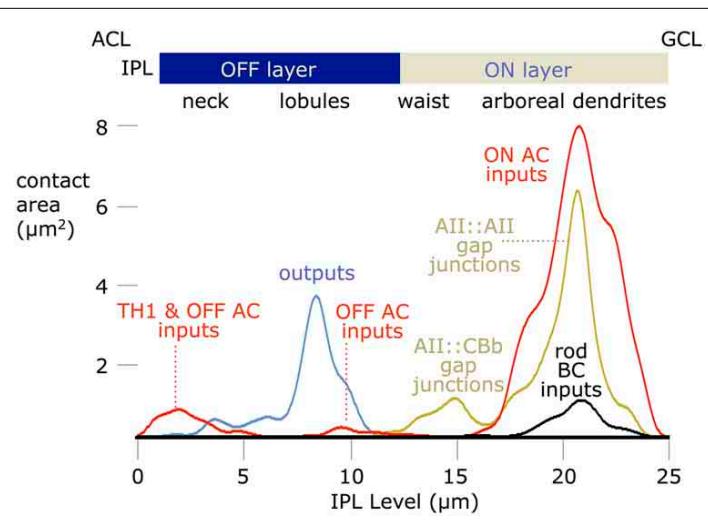

FIGURE 12 | Contact area profiles. Contact areas were computed at every level of the inner plexiform layer (IPL), where 0 is the amacrine cell layer $(A C L)$, and 25 is the ganglion cell layer (GCL). The ordinate scales presynaptic (outputs), postsynaptic (inputs) or gap junction contact areas for a typical All cell. The abscissa is the depth of the inner plexiform layer. were computed for a lateral traverse through every level of the inner plexiform layer (IPL), where 0 is the amacrine cell layer and 25 is the ganglion cell layer. mix of OFF amacrine cell and TH1 presumed ON synapses. Thus, the TH1 ON excitation is $\approx 1 / 3$ the $\mathrm{ON}$ coupling excitation area.

We can also parse the strengths of individual gap junctions for homocellular AII::AII and heterocellular AII::CBb coupling. The RC1 database includes includes 525 AII::AII and 172 AII::CBb coupling instances (Figure 13), with a mean \pm 1 SD gap junction diameter of $267 \pm 95 \mathrm{~nm}$ for AII::AII and $238 \pm 95 \mathrm{~nm}$ for AII::CBb pairings. The mean for heterocellular coupling is only about $11 \%$ smaller, but due to the large sample size is still highly significant ( 2 tailed homoscedastic $t$-test, $p=0.00052$ ). More to the point, however, the largest gap junctions made by AII::AII

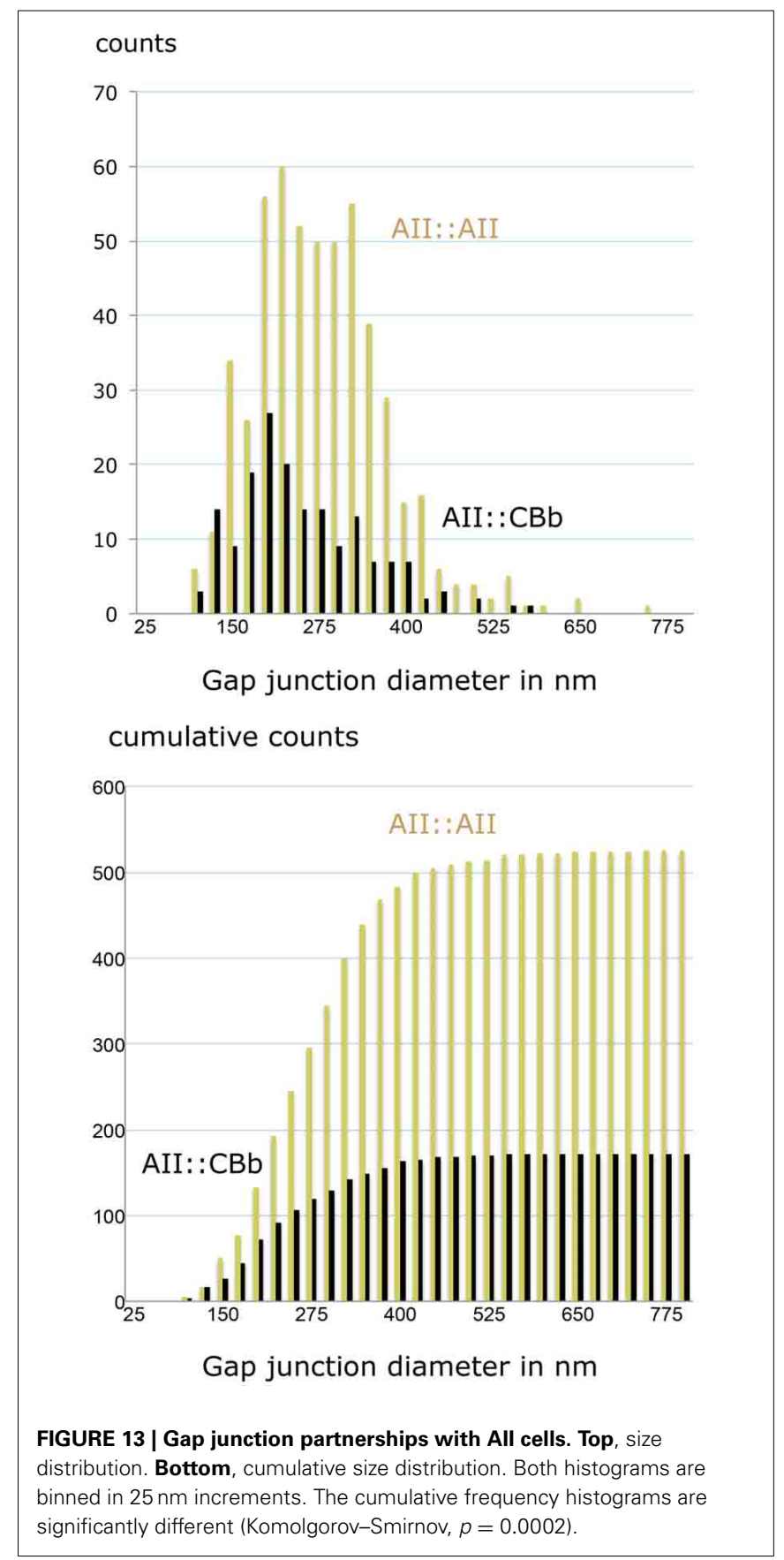


pairings (745 $\mathrm{nm}$ ) are $20 \%$ larger than made in AII::CBb pairings $(592 \mathrm{~nm})$ and the cumulative frequency distributions are significantly different. This corresponds to a $60 \%$ larger area for the largest homocellular versus heterocellular AII cell gap junctions.

\section{DISCUSSION}

\section{THE AII CELL IS A DENSE HUB}

The partnerships of AII cells (Table S1) establish it as a network hub of high density and complexity. The AII cell contacts every retinal bipolar cell, which requires recognizing 15 cell classes with four differential contact rules: (1) exclusively postsynaptic for rod bipolar cells; (2) exclusively coupling for most $\mathrm{CBb}$ ON cone bipolar cells; (3) mixed coupling and postsynaptic for CBb7 bipolar cells; and both presynaptic and postsynaptic for all $\mathrm{CBa} O \mathrm{OFF}$ bipolar cells, albeit sparsely. Within the arboreal dendrite zone, AII cells can distinguish between rod and cone ON bipolar cells without error, being postsynaptic for the former and coupled to the latter. Further, the putative blue selective $\mathrm{CBb} 7$ makes both synapses and gap junctions, supporting the notion that unique bipolar cell surface markers facilitate synapse formation and that contact type and weight is a deterministic, not a stochastic process. This specificity, precise weighting, and consistent topology across AII is the antithesis of adjustable functional weighting of networks to compensate for variable connectivity (Prinz et al., 2004).

In detail, our conclusions regarding the numbers and variances of rod bipolar cells contacting a single AII cell are different from measurements of Tsukamoto and Omi (2013) in mouse, where their coefficients of variation $(\mathrm{CV})$ are very similar for either number of rod bipolar cells or ribbon synapses contacting AII cells. This is almost certainly due to the small span of both mouse rod bipolar cell terminals and AII cells in the mouse $(\approx 10 \mu \mathrm{m})$, while rabbit rod bipolar cell terminals span $20-30 \mu \mathrm{m}$ and AII cells span $70 \mu \mathrm{m}$ or more, meaning that a single rod bipolar cell is unlikely to dominate connectivity. Thus, it is quite unlikely that randomly placed AII cell in rabbit will have low CV. This provides a robust test for synaptic precision, which in rabbit is revealed to be high (very low CV).

Further, All afferent signal flow from photoreceptors is shaped by the AII transfer function. The 28 cell classes make 36 kinds of contacts, which is greater than the contact diversity reported for any other cell type in any nervous system. It also understates the complexity of AII cells, as many other classes touch AII cells, but functional contact is rejected. Given that there are $\approx 60$ classes of neurons in the mammalian retina (Masland, 2001; Rockhill et al., 2002), the network graph of the retina shows that all neurons are within two hops from an AII cell, and almost half are directly connected. The scope of this connectivity, in turn, makes the entire retina a small-world system (Barthelemy and Amaral, 1999), despite its obvious dependence on multiple, tuned output channels manifest as ganglion cell diversity (Marc and Jones, 2002; Rockhill et al., 2002).

Further, the contact selectivity is completely regional in the AII cell. ON cone bipolar cell axons that touch AII lobules in the OFF layer never appear to form gap junctions, while all such axons that contact AII arboreal dendrites on the ON layer do so. This prevails despite the fact the ON cone bipolar cells can make functional presynaptic and postsynaptic specializations in the OFF layer (Dumitrescu et al., 2009; Hoshi et al., 2009; Lauritzen et al., 2012). It is also certain that we have underestimated the diversity of wide-field GABAergic amacrine cell interactions.

\section{THE NEW AII NETWORK}

With this tabulation we can revise Figure 2 to form a richer network description of AII cells (Figure 14). There are six separate type of sign-conserving inputs to AII cells. Starting with the neck region, $\mathrm{TH} 1$ axonal cells make sparse conventional synapses on AII cells. While these cells were first thought to be dual GABAergic/dopaminergic neurons, small molecule profiling in the rabbit retina establishes that they have the same signature as glutamatergic ganglion cells and definitely lack any inhibitory signature (Anderson et al., 2011b). TH1 axonal cells are predominantly ON cells (Zhang et al., 2007) and receive direct ribbon input from en passant ON cone bipolar cell axons (Dumitrescu et al., 2009; Hoshi et al., 2009; Lauritzen et al., 2012), and their effect on AII cells should be an ON transient signal. The path from cone $\rightarrow$ ON BC $\rightarrow$ TH1 AxC $\rightarrow$ AII cell is purely glutamatergic, and given that the nominal gain of each transfer is some value $n \gg 1$ (Marc et al., 2013), this synaptic chain has an amplification proportional to $n^{3}$ and may be the most sensitive photopic drive for AII cells. The low synapse number does not reduce this weighting significantly as the synaptic area is large. The second class of sign-conserving input is direct synaptic input from OFF cone bipolar cells (CBa cells) onto lobules. Despite the fact that every class of CBa cells makes some synapses onto AII lobules across the population, input to individual AII cells is low (2-5 synapses/cell) and the OFF ribbon synapse area weighting is approximately 20 -fold lower than the third class of sign-conserving input, synaptic ribbons from rod bipolar cells. The fourth sign-conserving input is synaptic ribbon drive from CBb7 cells. We have begun mapping these cells and there are only seven validated cells so far in the entire RC1 volume (compared to 104 rod bipolar cells and over $200 \mathrm{CBb}$ cells), as their arbors span well over $120 \mu \mathrm{m}$ each. Nevertheless, their connectivities are unique and every one provides 1-3 ribbon inputs to a nearby AII cells. While this drive may be relatively weak compared to other inputs, it could dominate given the right stimulus conditions. The final two classes of sign-conserving input are heterocellular AII::CBb coupling and homocellular AII::AII coupling. Our profiling of gap junctions suggest that homocellular coupling is $\approx 7$-fold stronger based on area than heterocellular coupling, assuming similar unitary connexin conductances. However, it appears that AII amacrine cell homocellular coupling is down-regulated by dopamine release and/or light adaptation (Mills and Massey, 1995; Bloomfield et al., 1997; Bloomfield, 2001) while heterocellular coupling is less strongly modulated. However, the regulation of AII::AII coupling may not be as simple as these early studies suggested (Hartveit and Veruki, 2012). In any case, AII::AII coupling may be attenuated in light adapted retinas, and the strength of $\mathrm{AII}: \mathrm{CBb}$ coupling may become dominant. The notion that these gap junctions are differentially regulated is consistent with the fact that AII::AII coupling is completely dependent on connexin 36 (Cx36) expression, whereas 


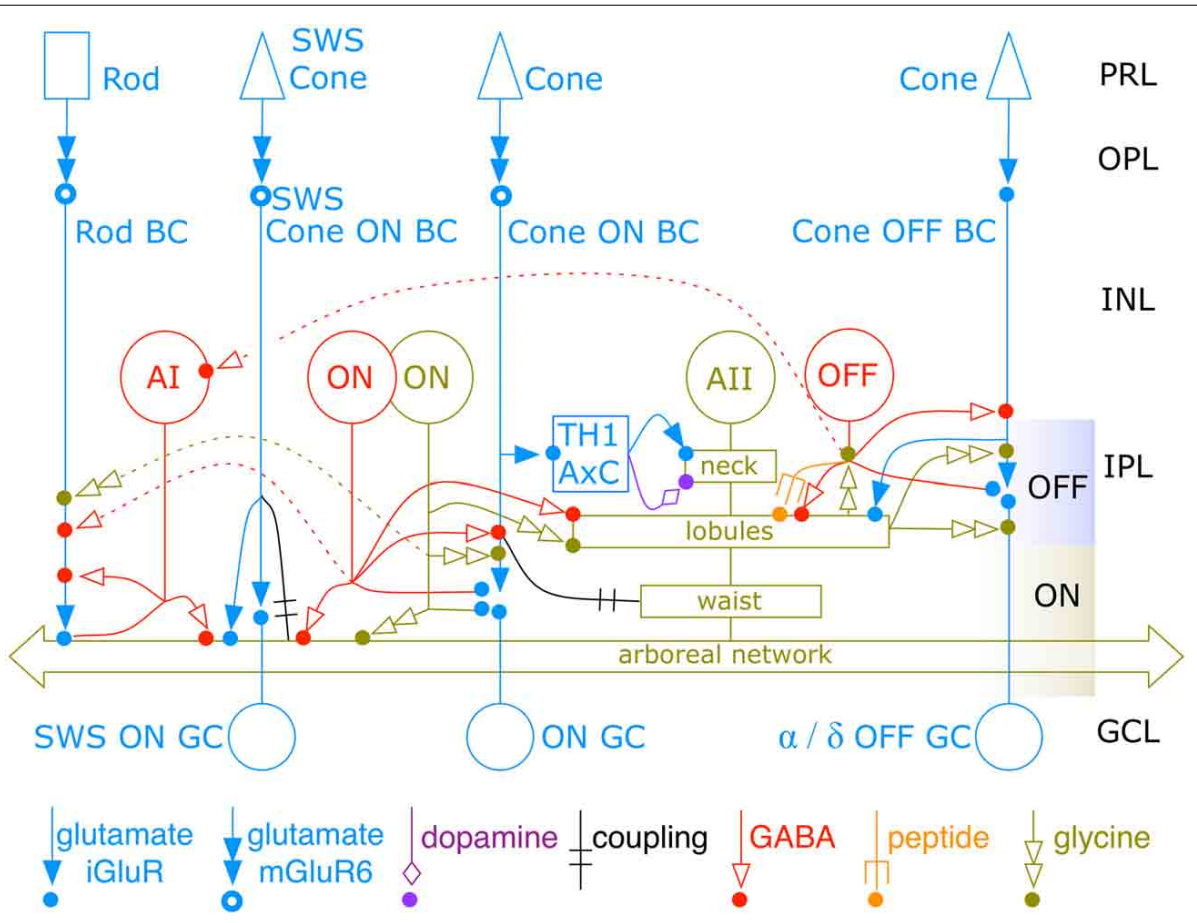

FIGURE 14 | The new All amacrine cell network. The complete All cell network spans 4 classes of excitatory glutamate inputs, three coupling partners, dopamine modulation, three wide-field GABAergic inputs, peptide modulation, narrow-field glycinergic input, and outputs to OFF bipolar cells, OFF inhibitory neurons and two classes of OFF ganglion cells. All classes of $\mathrm{CBb}$ (except $\mathrm{CBb} 7$ ) and $\mathrm{CBa}$ bipolar cells are lumped into single ON and OFF channels. Multiple classes of ON and OFF amacrine cells are lumped into single representative classes. Dashed lines show paths for cone $\rightarrow$ rod suppressive crossover. TH1 AxC is a dual glutamate/dopamine wide-field axonal cell. PRL, photoreceptor layer; OPL, outer plexiform layer; INL, inner nuclear layer; IPL, inner plexiform layer; GCL, ganglion cell layer. Icon key at bottom denotes connection types. The OFF band captures the All neck and lobules, which do not overlap with neighboring All cells. The ON band captures the waist and the heavily coupled arboreal network, which overlaps other All cells with a coverage factor of 4 . Colored dots denote postsynaptic sites for each modality.
AII::CBb coupling appears not to require Cx36 (Meyer et al., 2014).

$\mathrm{AII}: \mathrm{CBb}$ coupling engages all classes of $\mathrm{CBb} \mathrm{ON}$ cone bipolar cells. Thus, the physiological features of different types of $\mathrm{CBb}$ cells (e.g., Saszik and Devries, 2012) must readily be shared across the CBb::AII::CBb chain. How this plays out in ganglion cell drive based on targeting different bipolar cells remains to be clarified. Nevertheless, this supports a mechanistic emergence of selective connectivity patterns across cell classes, rather than a stochastic encounter-based connectivity, although whether this happens as a result of selective pruning or first intention or both remains to be resolved (Tian, 2011).

There are at least five major classes of AII interaction with inhibitory neurons. At the level of the lobules, AII cells are presynaptic and postsynaptic to two distinct classes of GABAergic feedback amacrine cells, one of which is peptidergic cell of unknown class that appears to make both conventional small vesicle and large peptide granule fusion sites on the lobules (Anderson et al., 2011b). AII lobule synaptic drive from amacrine cells is more prevalent than bipolar cell input by about 5-fold. Arboreal dndrites receive inhibition from at least three cells classes: sparse inputs from the classic AI amacrine cell and much more extensive inhibition from both wide-field cone-driven GABAergic and narrow-field glycinergic ON amacrine cells. Ultimately, each of these area weightings need to be combined with corresponding weights derived from physiological measures. The recent findings of Arman and Sampath (2012) suggest that this will be far from simple, but this is nevertheless the essential step in building a compact AII model.

We were not able to identify a unique axon-initial-segment process emerging from the AII neck as described by Cembrowski et al. (2012) using optical imaging or Tsukamoto and Omi (2013) using ultrastructure in the mouse. In rabbit AII cells, all lobular processes are long $(15-20 \mu \mathrm{m})$, longer than the axoninitial-segment described in mouse. Every AII lobular processes displayed either large or small lobule like domains with vesicles, and both presynaptic and postsynaptic specializations. Often, one appendage was higher than most, emerging from the top of the neck, but we found no ultrastructural specialization that could be attributed to enhanced voltage-gated sodium channel expression. We noted that AII cells often display membrane densities similar to those described by Tsukamoto and Omi (2013), but have not observed that they are restricted to any compartment.

\section{CROSSOVER}

Heterocellular coupling to ON cone bipolar cells and glycinergic output to OFF cone bipolar cells appears to be a prime mechanism for redistributing amplified rod signals into cone pathways. 
The threshold of OFF ganglion cells in particular appears to be set by glycine release from AII cells (Muller et al., 1988; Arman and Sampath, 2012). But these pathways (and probably others) clearly operate at photopic levels as well (Manookin et al., 2008; Münch et al., 2009). Though the ability of ON cone bipolar cells to drive lobule output from arboreal dendrite input seems probable, Arman and Sampath (2012) provide evidence in mouse against the AII $\rightarrow$ OFF BC path being a dominant control arm in the scotopic state. This is at odds with our anatomic weighting. Perhaps the scenario is different in mouse, but in rabbit, every OFF BC receives significant glycinergic input from both AII cells and other glycinergic ACs. But in mouse, OFF BC light responses show no effect of glycine blockade. OFF ganglion cells receive many fewer glycine inputs than bipolar cells, but in mouse the influence of strychnine on threshold is more potent. The explanation for this is unclear. Either glycinergic ON to OFF crossover inhibition through bipolar cells (AII $\rightarrow$ OFF BC $\rightarrow$ OFF and ONOFF ganglion cells) or direct mechanisms (AII $\rightarrow$ OFF $\alpha$ ganglion cell) could be operative at the photopic level (Molnar et al., 2009; Werblin, 2010). But the addition of glycinergic drive targeting inhibitory amacrine cells (Figure 14) that converge on the proximal dendrites of AI amacrine cells exposes an additional role for the AII cell in cone $\rightarrow$ rod crossover suppression networks (Marc et al., 2013). This may be a mechanism for fast mesopic switching between rod and cone vision and that operates by suppressing rod bipolar cell output when cone signals are dominant. The AII is also a recipient of cone-driven inhibition at the arboreal dendrite level (Figure 14), which may further suppress rod output signaling.

\section{EVOLUTION}

A distinguishing feature of mammals is the prevalence of rods (in most species) and the presence of the AII amacrine cell as a device to capture and amplify rod signals by driving them through a third ribbon synapse in the two arms of the cone pathway. As far as we know, non-mammalians do not exploit this mechanism and no homolog of the AII cell has yet been found, despite the abundance of narrow-field, multistratified and likely glycinergic amacrine cells in ectotherms. Most non-mammalians use mixed rod-cone bipolar cells as a merged scotopic-photopic mechanism to drive retinal ganglion cells (Ishida et al., 1980). Volume RC1 does provide some clues to the provenance of AII cells. If one removes all the rod components from the AII connectome (Figure 14), the vast majority of connections remain as an ON-OFF crossover system. Further, many non-mammalians (e.g., amphibians) display glycine signals in their ON bipolar cells (Marc et al., 1995; Yang and Yazulla, 1988), suggesting the presence of gap junctions between glycinergic amacrine cells and cone bipolar cells. Thus, the emergence of rod and rod bipolar cell proliferation in mammals could be the singular event that captured this crossover system as a scotopic amplifier (Dyer et al., 2009).

\section{ACKNOWLEDGMENTS}

This work was supported by National Institutes of Health (EY02576, EY015128, and EY014800), the National Science Foundation (0941717), the Thome Foundation, and an unrestricted grant from Research to Prevent Blindness.

\section{SUPPLEMENTARY MATERIAL}

The Supplementary Material for this article can be found online at: http://www.frontiersin.org/journal/10.3389/fncir. 2014.00104/abstract

Table S1 | A comprehensive list of all All amacrine cell partnerships. sourceMarc-Frontiers-2014-Table-1.pdf.

\section{REFERENCES}

Anderson, J. R., Grimm, B., Mohammed, S., Jones, B. W., Spaltenstein, J., Koshevoy, P., et al. (2011a). The Viking viewer: scalable multiuser annotation and summarization of large connectomics datasets. J. Microsc. 241, 13-28. doi: 10.1111/j.1365-2818.2010.03402.x

Anderson, J. R., Jones, B. W., Watt, C. B., Shaw, M. V., Yang, J.-H., Demill, D., et al. (2011b). Exploring the retinal connectome. Mol. Vis. 17, 355-379. Available online at: http://www.molvis.org/molvis/v17/a41

Anderson, J. R., Jones, B. W., Yang, J.-H., Shaw, M. V., Watt, C. B., Koshevoy, P., et al. (2009). A computational framework for ultrastructural mapping of neural circuitry. PLoS Biol. 7:e1000074. doi: 10.1371/journal.pbio.1000074

Arman, A. C., and Sampath, A. P. (2012). Dark-adapted response threshold of OFF ganglion cells is not set by OFF bipolar cells in the mouse retina. J. Neurophysiol. 107, 2649-2659. doi: 10.1152/jn.01202.2011

Attwell, D., Wilson, M., and Wu, S. M. (1984). A quantitative analysis of interactions between photoreceptors in the salamander (Ambystoma) retina. J. Physiol. 352, 703-737.

Barthelemy, M., and Amaral, L. A. N. (1999). Small-world networks: evidence for a crossover picture. Phys. Rev. Lett. 82, 3180-3183.

Bloomfield, S. A. (2001). Plasticity of AII amacrine cell circuitry in the mammalian retina. Prog. Brain Res. 131, 185-200. doi: 10.1016/S0079-6123(01)31016-6

Bloomfield, S. A., Xin, D. Y., and Osborne, T. (1997). Light-induced modulation of coupling between AII amacrine cells in the rabbit retina. Vis. Neurosci. 14, 565-576.

Cembrowski, M. S., Logan, S. M., Tian, M., Jia, L., Li, W., Kath, W. L., et al. (2012). The mechanisms of repetitive spike generation in an axonless retinal interneuron. Cell Rep. 1, 155-166. doi: 10.1016/j.celrep.2011.12.006

Da Costa, N. M., and Martin, K. A. C. (2009). Selective targeting of the dendrites of corticothalamic cells by thalamic afferents in area 17 of the cat. J. Neurosci. 29, 13919-13928. doi: 10.1523/JNEUROSCI.2785-09.2009

Devries, S. H., and Baylor, D. A. (1995). An alternative pathway for signal flow from rod photoreceptors to ganglion cells in mammalian retina. Proc. Natl. Acad. Sci. U.S.A. 92, 10658-10662.

Dumitrescu, O. N., Pucci, F. G., Wong, K. Y., and Berson, D. M. (2009). Ectopic retinal ON bipolar cell synapses in the OFF inner plexiform layer: contacts with dopaminergic amacrine cells and melanopsin ganglion cells. J. Comp. Neurol. 517, 226-244. doi: 10.1002/cne.22158

Dyer, M. A., Martins, R., Da Silva Filho, M., Muniz, J. A. P. C., Silveira, L. C. L., Cepko, C. L., et al. (2009). Developmental sources of conservation and variation in the evolution of the primate eye. Proc. Natl. Acad. Sci. U.S.A. 106, 8963-8968. doi: 10.1073/pnas.0901484106

Famiglietti, E. V. (2008). Wide-field cone bipolar cells and the blue-ON pathway to color-coded ganglion cells in rabbit retina. Vis. Neurosci. 25, 53-66. doi: 10.1017/S0952523808080061

Famiglietti, E. V. Jr., Kaneko, A., and Tachibana, M. (1975). Neuronal architecture of on and off pathways to ganglion cells in carp retina. Science (Washington, D.C.) $198,1267-1269$.

Frishman, L. J. (2006). "The origins of the electroretinogram," in Principles and Practice of Clinical Electroretinography of Vision, 2nd Edn., eds. J. R. Heckenlively and G. B. Arden (Cambridge, MA: MIT Press), 139-184.

Grant, G. B., and Dowling, J. E. (1996). On bipolar cell responses in the teleost retina are generated by two distinct mechanisms. J. Neurophysiol. 76, 3842-3849.

Hartveit, E., and Veruki, M. L. (2012). Electrical synapses between AII amacrine cells in the retina: function and modulation. Brain Res. 1487, 160-172. doi: 10.1016/j.brainres.2012.05.060

Hoshi, H., Liu, W.-L., Massey, S. C., and Mills, S. L. (2009). ON inputs to the OFF layer: bipolar cells that break the stratification rules of the retina. J. Neurosci. 29, 8875-8883. doi: 10.1523/jneurosci.0912-09.2009

Ishida, A. T., Stell, W. K., and Lightfoot, D. O. (1980). Rod and cone inputs to bipolar cells in goldfish retina. J. Comp. Neurol. 191, 315-335. 
Jones, B. W., Watt, C. B., Frederick, J. M., Baehr, W., Chen, C. K., Levine, E. M., et al. (2003). Retinal remodeling triggered by photoreceptor degenerations. J. Comp. Neurol. 464, 1-16. doi: 10.1002/cne.10703

Kolb, H., and Famiglietti, E. V. (1974). Rod and cone pathways in the inner plexiform layer of cat retina. Science 186, 47-49.

Lauritzen, J. S., Anderson, J. R., Jones, B. W., Watt, C. B., Mohammed, S., Hoang, J. V., et al. (2012). ON cone bipolar cell axonal synapses in the OFF inner plexiform layer of the rabbit retina. J. Comp. Neurol. 521, 977-1000. doi: $10.1002 /$ cne. 23244

Lauritzen, J. S., Hoang, J. V., Sigulinsky, C., Jones, B. W., Anderson, J. R., Watt, C. B., et al. (2013). Tiered cross-class bipolar cell gap junctional coupling in the rabbit retina. Invest. Ophthal. 54:1754.

Li, W., Chen, S., and Devries, S. H. (2010). A fast rod photoreceptor signaling pathway in the mammalian retina. Nat. Neurosci. 13, 414-416. doi: 10.1038/ nn.2507

Manookin, M. B., Beaudoin, D. L., Ernst, Z. R., Flagel, L. J., and Demb, J. B. (2008). Disinhibition combines with excitation to extend the operating range of the OFF visual pathway in daylight. J. Neurosci. 28, 4136-4150. doi: 10.1523/JNEUROSCI.4274-07.2008

Marc, R. E., Anderson, J. R., Jones, B. W., Watt, C. B., and Lauritzen, J. S. (2013). Retinal Connectomics: towards complete, accurate networks. Prog. Retin. Eye Res. 37, 141-162. doi: 10.1016/j.preteyeres.2013.08.002

Marc, R. E., and Jones, B. W. (2002). Molecular phenotyping of retinal ganglion cells. J. Neurosci. 22, 412-427.

Marc, R. E., Jones, B. W., Sigulinsky, C., Anderson, J. R., and Lauritzen, J. S. (2014). "High-Resolution Synaptic Connectomics," in New Techniques in Neuroscience: Physical, Optical, and Quantitative Approaches, ed D. Adams (Berlin: Springer) (in press).

Marc, R. E., and Liu, W. (2000). Fundamental GABAergic amacrine cell circuitries in the retina: nested feedback, concatenated inhibition, and axosomatic synapses. J. Comp. Neurol. 425, 560-582. doi: 10.1002/1096-9861(20001002) 425:4<560::AID-CNE7>3.0.CO;2-D

Marc, R. E., Murry, R. F., and Basinger, S. F. (1995). Pattern recognition of amino acid signatures in retinal neurons. J. Neurosci. 15, 5106-5129.

Masland, R. H. (2001). Neuronal diversity in the retina. Curr. Opin. Neurobiol. 11, 431-436. doi: 10.1016/S0959-4388(00)00230-0

Massey, S. C. (2008). "Circuit functions of gap junctions in the mammalian retina," in The Senses, eds R. H. Masland and T. Albright (San Diego, CA: Academic Press), 457-472.

Mastronarde, D. N. (2005). Automated electron microscope tomography using robust prediction of specimen movements. J. Struct. Biol. 152, 36-51. doi: 10.1016/j.jsb.2005.07.007

McGuire, B. A., Stevens, J. K., and Sterling, P. (1984). Microcircuitry of bipolar cells in cat retina. J. Neurosci. 4, 2920-2938.

Meyer, A., Hilgen, G., Dorgau, B., Sammler, E. M., Weiler, R., Monyer, H., et al. (2014). AII amacrine cells discriminate between heterocellular and homocellular locations when assembling connexin36-containing gap junctions. J. Cell Sci. 127, 1190-1202. doi: 10.1242/jcs. 133066

Mills, S. L., and Massey, S. C. (1995). Differential properties of two gap junctional pathways made by AII amacrine cells. Nature 377, 734-737.

Molnar, A., Hain-Ann, H., Roska, B., and Werblin, F. S. (2009). Crossover inhibition in the retina: circuitry that compensates for nonlinear rectifying synaptic transmission. J. Comput. Neurosci. 27, 569-590. doi: 10.1007/s10827-0090170-6

Muller, F., Wassle, H., and Voigt, T. (1988). Pharmacological modulation of the rod pathway in the cat retina. J. Neurophysiol. 59, 1657-1672.

Münch, T. A., Da Silveira, R. A., Siegert, S., Viney, T. J., Awatramani, G. B., and Roska, B. (2009). Approach sensitivity in the retina processed by a multifunctional neural circuit. Nat. Neurosci. 12, 1308-1316. doi: 10.1038/nn.2389

Naka, K., Marmarelis, P. Z., and Chan, R. Y. (1975). Morphological and functional identifications of catfish retinal neurons. III. Functional identification. J. Neurophysiol. 38, 92-131.

Pang, J. J., Gao, F., Lem, J., Bramblett, D. E., Paul, D. L., and Wu, S. M. (2010). Direct rod input to cone BCs and direct cone input to rod BCs challenge the traditional view of mammalian BC circuitry. Proc. Natl. Acad. Sci. U.S.A. 107, 395-400. doi: 10.1073/pnas.0907178107

Pang, J. J., Gao, F., Paul, D. L., and Wu, S. M. (2012). Rod, M-cone and M/Scone inputs to hyperpolarizing bipolar cells in the mouse retina. J. Physiol. 590, 845-854. doi: 10.1113/jphysiol.2011.224113
Prinz, A. A., Bucher, B., and Marder, E. (2004). Similar network activity from disparate circuit parameters. Nat. Neurosci. 7, 1345-1352. doi: 10.1038/ nn 1352

Rockhill, R. L., Daly, F. J., Macneil, M. A., Brown, S. P., and Masland, R. H. (2002). The diversity of ganglion cells in a mammalian retina. J. Neurosci. 22, 3831-3843.

Saito, T., Kondo, H., and Toyoda, J. I. (1979). Ionic mechanisms of two types of oncenter bipolar cells in the carp retina. I. The responses to central illumination. J. Gen. Physiol. 73, 73-90.

Saszik, S., and Devries, S. H. (2012). A mammalian retinal bipolar cell uses both graded changes in membrane voltage and all-or-nothing $\mathrm{Na}+$ spikes to encode light. J. Neurosci. 32, 297-307. doi: 10.1523/jneurosci.2739-08.2012

Saszik, S. M., Robson, J. G., and Frishman, L. J. (2002). The scotopic threshold response of the dark-adapted electroretinogram of the mouse. J. Physiol. 543(Pt 3), 899-916. doi: 10.1113/jphysiol.2002.019703

Scholes, J. H. (1975). Colour receptors, and their synaptic connexions, in the retina of a cyprinid fish. Philos. Trans. R. Soc. Lond. B. Biol. Sci. 270, 61-118.

Scholes, J., and Morris, J. (1973). Receptor-bipolar connectivity patterns in fish retina. Nature 241, 52-54.

Soucy, E., Wang, Y., Nirenberg, S., Nathans, J., and Meister, M. (1998). A novel signaling pathway from rod photoreceptors to ganglion cells in mammalian retina. Neuron 21, 481-493.

Strettoi, E., Raviola, E., and Dacheux, R. F. (1992). Synaptic connections of the narrow-field, bistratified rod amacrine cell (AII) in the rabbit retina. J. Comp. Neurol. 325, 152-168.

Tian, N. (2011). Developmental mechanisms that regulate retinal ganglion cell dendritic morphology. Dev. Neurobiol. 71, 1297-1309. doi: 10.1002/dneu. 20900

Tsukamoto, Y., Morigiwa, K., Ishii, M., Takao, M., Iwatsuki, K., Nakanishi, S., et al. (2007). A novel connection between rods and ON cone bipolar cells revealed by ectopic metabotropic glutamate receptor 7 (mGluR7) in mGluR6-deficient mouse retinas. J. Neurosci. 27, 6261-6267. doi: 10.1523/JNEUROSCI.564606.2007

Tsukamoto, Y., Morigiwa, K., Ueda, M., and Sterling, P. (2001). Microcircuits for night vision in mouse retina. J. Neurosci. 21, 8616-8623.

Tsukamoto, Y., and Omi, N. (2013). Functional allocation of synaptic contacts in microcircuits from rods via rod bipolar to AII amacrine cells in the mouse retina. J. Comp. Neurol. 521, 3541-3555. doi: 10.1002/cne.23370

Wang, G. Y. (2006). Unique functional properties of the APB sensitive and insensitive rod pathways signaling light decrements in mouse retinal ganglion cells. Vis. Neurosci. 23, 127-135. doi: 10.1017/S0952523806231110

Werblin, F. S. (2010). Six different roles for crossover inhibition in the retina: correcting the nonlinearities of synaptic transmission. Vis. Neurosci. 27, 1-8. doi: 10.1017/S0952523810000076

Yang, C. Y., and Yazulla, S. (1988). Light microscopic localization of putative glycinergic neurons in the larval tiger salamander retina by immunocytochemical and autoradiographical methods. J. Comp. Neurol. 272, 343-357.

Zhang, D.-Q., Zhou, T.-R., and McMahon, D. G. (2007). Functional heterogeneity of retinal dopaminergic neurons underlying their multiple roles in vision. J. Neurosci. 27, 692-699. doi: 10.1523/JNEUROSCI.4478-06.2007

Conflict of Interest Statement: Robert E. Marc is a principal of Signature Immunologics, Inc., manufacturer of some of the antibodies used in this work. The authors declare that the research was conducted in the absence of any commercial or financial relationships that could be construed as a potential conflict of interest.

Received: 16 April 2014; accepted: 08 August 2014; published online: 04 September 2014.

Citation: Marc RE, Anderson JR, Jones BW, Sigulinsky CL and Lauritzen JS (2014) The AII amacrine cell connectome: a dense network hub. Front. Neural Circuits 8:104. doi: 10.3389/fncir.2014.00104

This article was submitted to the journal Frontiers in Neural Circuits.

Copyright (C) 2014 Marc, Anderson, Jones, Sigulinsky and Lauritzen. This is an openaccess article distributed under the terms of the Creative Commons Attribution License (CC BY). The use, distribution or reproduction in other forums is permitted, provided the original author(s) or licensor are credited and that the original publication in this journal is cited, in accordance with accepted academic practice. No use, distribution or reproduction is permitted which does not comply with these terms. 